\title{
Ag Doped ZnO Thin Films Synthesized by Spray Coating Technique for Methylene Blue Photodegradation under UV Irradiation
}

\author{
Heri Sutanto, ${ }^{1}$ Singgih Wibowo, ${ }^{1}$ Iis Nurhasanah, ${ }^{1}$ Eko Hidayanto, ${ }^{1}$ and H. Hadiyanto ${ }^{2}$ \\ ${ }^{1}$ Department of Physics, Diponegoro University, Jalan Prof. Soedarto, SH, Tembalang, Semarang 50275, Indonesia \\ ${ }^{2}$ Department of Chemical Engineering, Diponegoro University, Jalan Prof. Soedarto, SH, Tembalang, Semarang 50275, Indonesia \\ Correspondence should be addressed to Heri Sutanto; herisutanto@undip.ac.id
}

Received 24 October 2015; Revised 11 January 2016; Accepted 1 February 2016

Academic Editor: Bhaskar Kulkarni

Copyright ( $\odot 2016$ Heri Sutanto et al. This is an open access article distributed under the Creative Commons Attribution License, which permits unrestricted use, distribution, and reproduction in any medium, provided the original work is properly cited.

Silver (Ag) substituted $\mathrm{ZnO}$ thin films were successfully deposited onto glass substrates by spray coating technique. Structure, morphology, and optical properties were evaluated by X-ray diffractometer (XRD), scanning electron microscopy (SEM), and UVVis spectrophotometer, respectively. XRD spectra had polycrystalline wurtzite structure; SEM images showed that thin films had different surface morphology at different Ag doping concentration. From transmittance spectra, thin films transparency decreased as well as band gap energy along with increase of Ag doping concentration. Methylene blue (MB) solution was used as a pollutant in the photodegradation studies. Under UV light irradiation, the optimal Ag doping is $25 \%$, with $83 \%$ of the decolorizing efficiencies after $3 \mathrm{~h}$ irradiation time and apparent constant $\left(k_{\text {app }}\right)$ about $9.69 \times 10^{-3} \mathrm{~min}^{-1}$.

\section{Introduction}

Indonesia has high number of textile industries which usually emit effluents directly into the environment. The effluents contain dyes, oils, and other chemical substances that are so harmful to the environment. The current treatment of textile industrial waste water requires high amount of chemicals and longer treatment time. Therefore an advance technology for treating waste water before being discharge into the environment is required. One of the technologies is by using a photocatalytic treatment to decompose organic pollutants including dyes and other harmless compounds like $\mathrm{CO}_{2}$ and $\mathrm{H}_{2} \mathrm{O}$ [1]. One of the semiconductors that now gain the attention of researchers as a photocatalyst materials is Zinc oxide $(\mathrm{ZnO})[2]$.

$\mathrm{ZnO}$ is a direct band gap semiconductor and is found to be useful in various applications such as photocatalysts, electronics, and cosmetics [1]. However, for photocatalytic application, it is desirable that $\mathrm{ZnO}$ should absorb not only UV but also visible light due to the fact that visible light accounts for $45 \%$ of energy in the solar radiation, while UV light accounts for less than 10\%. Addition of cations (transition metals) and anions (nitrogen, sulfur, carbon, or boron) into the semiconductor has been extensively studied to enhance the activity of photocatalyst $[3,4]$.

Addition of metal into $\mathrm{ZnO}$ using appropriate dopant and method can improve their applications performance. As an example in the photocatalytic application, $\mathrm{ZnO}$ can be added with Ag elements to improve efficiency. The Ag ions can act as acceptors in $\mathrm{ZnO}$ and may change $\mathrm{Zn}$ ions. Moreover, the addition of $\mathrm{Ag}$ ions can also reduce the energy gap in semiconductors so it can increase the absorption of light wavelength [5-7].

There are various methods that can be used to create a $\mathrm{ZnO}$ thin film such as pulsed laser deposition (PLD) [8], spray pyrolysis [9], metal oxide chemical vapor deposition (MOCVD) [10], and sol gel [11]. Sol gel is one of the most widely used methods because it is easy to prepare and of low cost. In this study, we made $\mathrm{Ag}$ substituted $\mathrm{ZnO}$ thin films by sol gel method. In order to test the photocatalytic activity, we used methylene blue (MB) as a pollutant and photodegradation conducted for $3 \mathrm{~h}$ under UV light irradiation. The objective of this paper is to evaluate the substitution high 
concentration $\mathrm{Ag}$ into $\mathrm{ZnO}$ and to evaluate its application for methylene blue (MB) degradation.

\section{Experiment}

Ag substituted $\mathrm{ZnO}(\mathrm{Ag}-\mathrm{ZnO})$ thin films were prepared by using sol gel spray coating technique onto glass substrates. Zinc acetate $\mathrm{Zn}\left(\mathrm{CH}_{3} \mathrm{COO}\right)_{2} \cdot 2 \mathrm{H}_{2} \mathrm{O}$ (Merck, 99.5\%) and silver acetate $\left(\mathrm{CH}_{3} \mathrm{COOAg}\right)$ (Sigma Aldrich, 99\%) were used as $\mathrm{ZnO}$ and Ag source, respectively. Prior to using glass substrates for Ag-ZnO deposition, they were cleaned with acetone, methanol, and deionized water. An appropriate quantity of silver acetate powder was dropped into the zinc acetate solution to accomplish different doping concentration (i.e., $0 \mathrm{~mol} \%, 5 \mathrm{~mol} \%$, $10 \mathrm{~mol} \%, 15 \mathrm{~mol} \%$, $20 \mathrm{~mol} \%$, and $25 \mathrm{~mol} \%$ ) and subsequently the initial and deposited samples are denoted by ZA5, ZA10, ZA15, ZA20, and ZA25, respectively.

The structural and morphological characterizations were carried out using Shimadzu Maxima 7000 X-ray diffractometer with $\mathrm{CuK} \alpha$ radiation (1.5405 $\AA$ ) and scanning electron microscopy (SEM) JEOL-JSM 6510 LA, respectively. The optical study was carried out using UV-Vis spectrophotometer (Shimadzu 1240 SA).

The photocatalytic test was performed in an aqueous solution using methylene blue $(\lambda=664 \mathrm{~nm})$ as the probe molecule. The samples were irradiated with UV (A) light (10 W UV tube, Aquaco). The Ag- ZnO films were horizontally fixed in the middle of beaker. The dye solution $(40 \mathrm{~mL})$ and samples were irradiated with light source placed horizontally above the beaker. The photodegradation of the dye was followed by measuring the absorption spectra at regular interval (every $30 \mathrm{~min}$ ) using a UV-Vis spectrophotometer (Shimadzu 1240 SA).

MB degradation efficiency $(\eta)$ was calculated according to

$$
\eta=\frac{\left(C_{0}-C\right)}{C_{0}} \times 100
$$

where $C_{0}$ represents the initial concentration and $C$ represents the concentration after $t$ minutes of photocatalysis.

\section{Results and Discussion}

3.1. X-Ray Diffractogram (XRD) Analysis. The changes in the structure and phase identification of $\mathrm{Ag}-\mathrm{ZnO}$ thin films were conducted by XRD analysis. The diffracting angle $(2 \theta)$ was varied between $10^{\circ}$ and $90^{\circ}$ and the spectra were recorded for all the samples which are shown in Figure 1. All the films show polycrystalline with mixed phases of $\mathrm{Ag}$ and $\mathrm{ZnO}$. The diffraction peaks corresponding to $\mathrm{ZnO}$ and $\mathrm{Ag}$ are in good agreement with standard JCPDS data card \#36-1451 and $\# 45-1027$, respectively. The diffraction peaks at $(2 \theta) 31.76^{\circ}$, $34.42^{\circ}, 36.24^{\circ}$, and $56.60^{\circ}$ are corresponding to hexagonal wurtzite $\mathrm{ZnO}$ phase with plane (100), (002), (101), and (110), respectively, while the diffraction peaks at $38.16^{\circ}$ and $44.40^{\circ}$ are related to the Ag phase with planes (111) and (200), respectively.

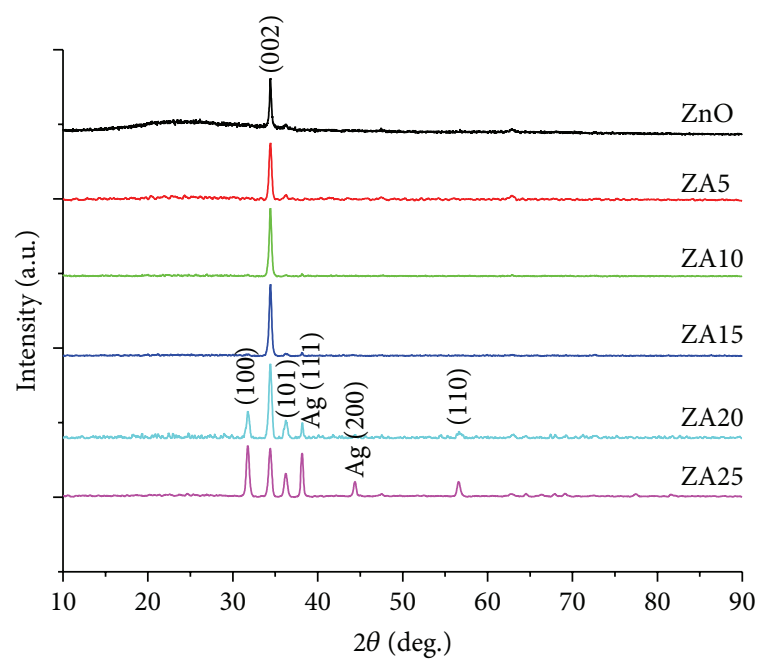

Figure 1: X-ray pattern of Ag-ZnO thin films prepared by thermal spray coating at $450^{\circ} \mathrm{C}$.

TABLE 1: Different interplanar spacing $d_{h k l}$ of Ag-ZnO sprayed thin films.

\begin{tabular}{lccc}
\hline & $d_{002}(\AA)$ & $d_{101}(\AA)$ & $c(\AA)$ \\
\hline ZnO & 2.6019 & 2.4780 & 5.2039 \\
ZA5 & 2.6034 & 2.4768 & 5.2067 \\
ZA10 & 2.6032 & 2.4761 & 5.2064 \\
ZA15 & 2.6031 & 2.4745 & 5.2061 \\
ZA20 & 2.6037 & 2.4756 & 5.2073 \\
ZA25 & 2.6050 & 2.4768 & 5.2101 \\
\hline
\end{tabular}

The interplanar spacing $d_{h k l}$ values of given Miller indices $h, k$, and $l$ of $\mathrm{Ag}$ doped $\mathrm{ZnO}$ thin films were also calculated by using Bragg equation as follows [12]:

$$
2 d_{h k l} \sin \theta=n \lambda
$$

where $n$ is the order of diffraction (usually $n=1$ ) and $\lambda$ is the X-ray wavelength. The plane spacing is related to the lattice constants $a, c$ and the Miller indices in $\mathrm{ZnO}$ hexagonal structure by the following equation [12]:

$$
\frac{1}{d_{h k l}^{2}}=\frac{4}{3}\left(\frac{h^{2}+h k+k^{2}}{a^{2}}\right)+\frac{l^{2}}{c^{2}} .
$$

Both lattice parameters $a$ and $c$ for the hexagonal closedpacked (HCP) are calculated via (002) and (101) orientations [12]. Table 1 summarizes also the calculated values of interplanar spacing $d_{h k l}$ of Ag doped $\mathrm{ZnO}$ thin films.

It can be seen from the results that the value of $c$ in the $\mathrm{ZnO}$ layer is greater than the standard value of $c_{o} \mathrm{ZnO}$ powder $(0.5205 \mathrm{~nm})$ [13]. Increasing value of $c$ is caused by a radius of $\mathrm{Ag}^{+}(1.26 \AA)$ which is greater than $\mathrm{Zn}^{2+}(0.74 \AA)$ when $\mathrm{Ag}$ is on the $\mathrm{Zn}$ site [13]. An increase in the lattice parameter can be also caused by interstitial incorporation of Ag ions into the lattice or Ag ion substitution of the $\mathrm{Zn}$ ions [13]. 


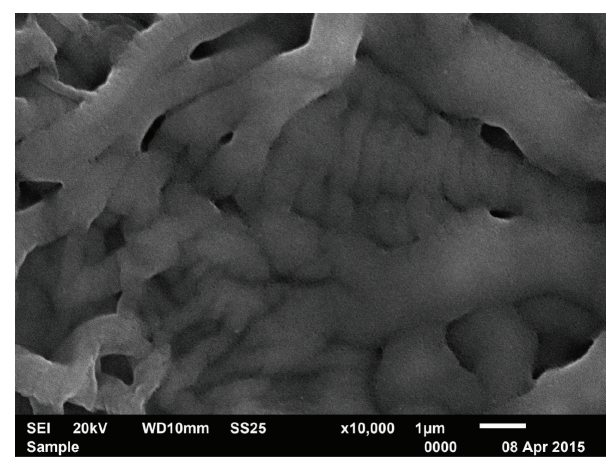

(a)

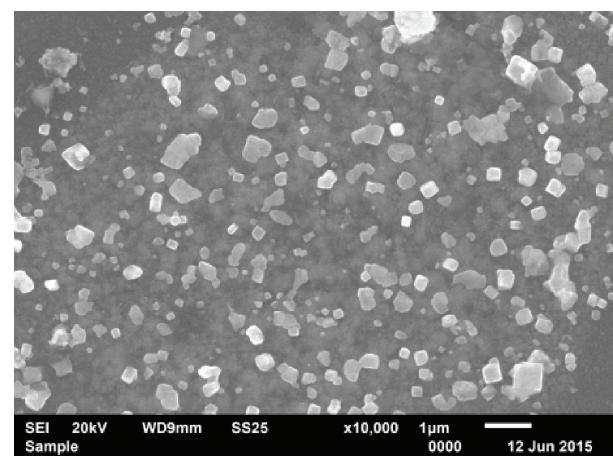

(c)

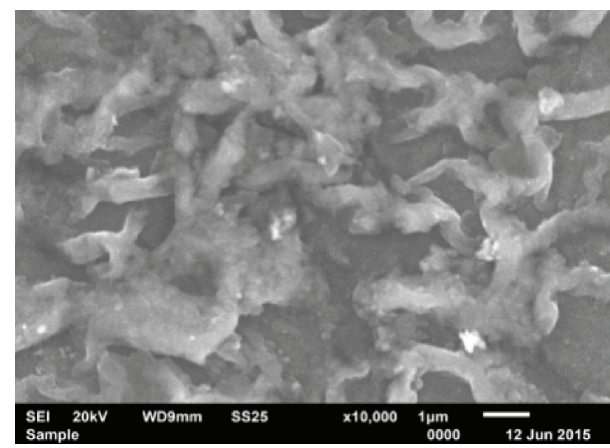

(e)

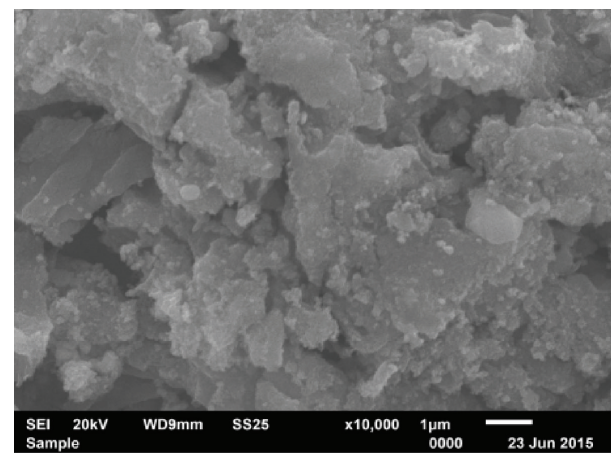

(b)

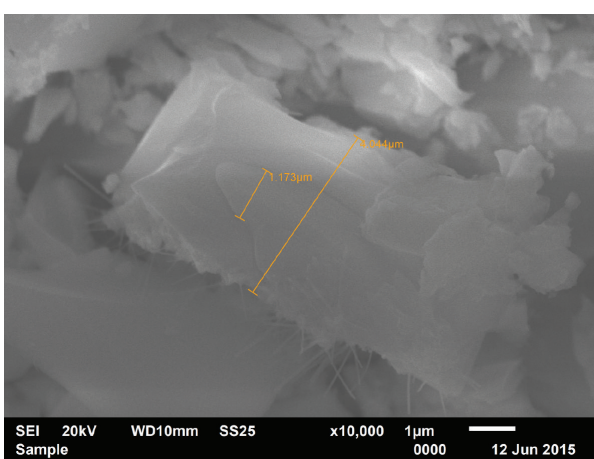

(d)

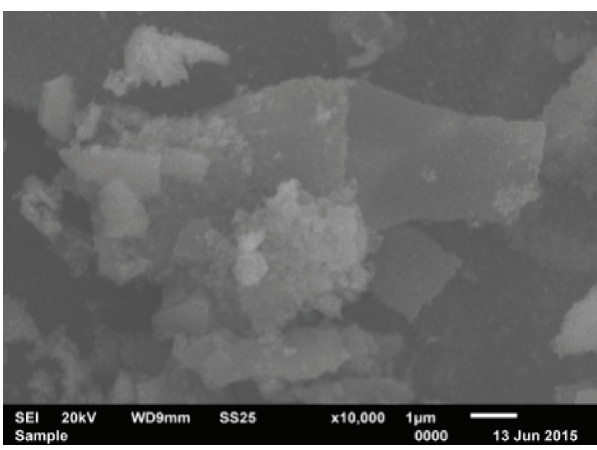

(f)

Figure 2: SEM images of (a) ZnO, (b) ZA5, (c) ZA10, (d) ZA15, (e) ZA20, and (f) ZA25.

TABLE 2: FWHM and grain size of Ag-ZnO sprayed thin films.

\begin{tabular}{lccc}
\hline & $2 \theta$ & FWHM $(\theta)$ & $D(\mathrm{~nm})$ \\
\hline ZnO & 34.4127 & 0.3305 & 24.7472 \\
ZA5 & 34.4204 & 0.3720 & 21.9845 \\
ZA10 & 34.4224 & 0.3579 & 22.8564 \\
ZA15 & 34.4245 & 0.3644 & 22.4475 \\
ZA20 & 34.4165 & 0.4159 & 19.6658 \\
ZA25 & 34.3977 & 0.4219 & 19.3861 \\
\hline
\end{tabular}

Table 2 depicts the grain size $D$ values that were estimated from (002) diffraction lines of $\mathrm{ZnO}$ free and $\mathrm{Ag}$ doped $\mathrm{ZnO}$ thin films using Scherrer formula [12]:

$$
D=\frac{k \lambda}{\beta_{1 / 2} \cos \theta},
$$

where $k=0.90$ is Scherrer constant, $\beta_{1 / 2}$ is the width at half-maximum, and $\lambda=1.54 \AA$ is the wavelength of $\mathrm{CuK} \alpha$ radiation.

3.2. Scanning Electron Microscopy (SEM) Analysis. The surface morphological study of the synthesized thin films was carried out using scanning electron microscopy (SEM). Figures 2(a)-2(f) show the SEM images with $\times 10.000$ magnification of all samples deposited at $450^{\circ} \mathrm{C}$ onto glass substrates. SEM images reveal that the films surface are different in each $\mathrm{Ag}$ concentration. At $\mathrm{ZnO}$ we found that the surface has thread-like morphology. ZA5 morphology does not have uniform surface, while in ZA10 a lot of particles in uniform size are clearly shown. ZA15 shows that the film has nonuniform surface. Thread-like morphology is shown in ZA20. The same result was observed by Tarwal and Patil [14]. At ZA25, the film surface is not uniform just like ZA5 and ZA15. Shidpour 


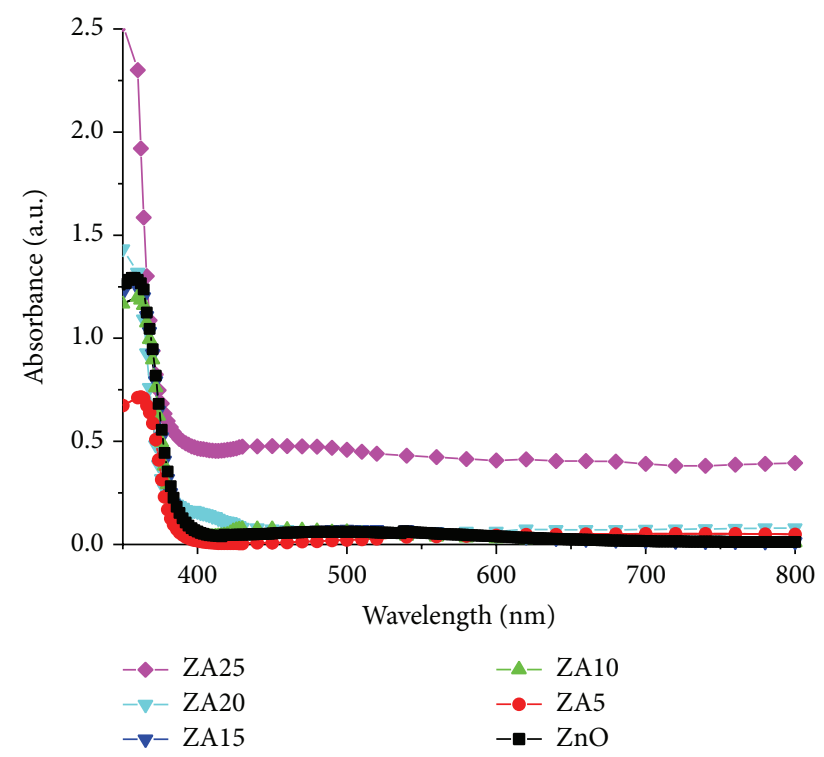

Figure 3: UV-Vis absorption spectra of Ag- $\mathrm{ZnO}$ thin films.

et al. [15] showed that the different surface morphology determined the outcome of photocatalytic activity, which is indicated by nanowire-like morphology as having higher photocatalytic activity than nanoporous.

3.3. UV-Vis Spectrophotometer Analysis. Figure 3 shows the absorbance spectra as a function of wavelength for Ag$\mathrm{ZnO}$ thin films deposited on glass substrates prepared by sol gel spray coating. It can be seen that increase of Ag concentrations makes slightly shifts of absorption edge to higher wavelengths. In addition, the nearly flat spectra are shown in the higher wavelength area. This is due to the larger amount of $\mathrm{Ag}$, increasing the substitution of $\mathrm{Zn}$ ion by $\mathrm{Ag}$ ions.

Figure 4 shows the transmittance spectra for $\mathrm{Ag}-\mathrm{ZnO}$ thin films. The transmittance spectra are formed by interference of light at the interface between the films and the substrate. Transmittance spectra of $\mathrm{Ag}-\mathrm{ZnO}$ films in the visible region decrease from 90 to $30 \%$ as the $\mathrm{Ag}$ percentage increases. This decrease in the transmittance value of the Ag$\mathrm{ZnO}$ thin films may be due to the grain boundary scattering. It is also caused by surface plasmon resonance (SPR) related phenomenon of Ag nanoparticles which can absorb the visible light.

Absorption coefficient and band gap for the direct band gap semiconductor obey the following relationship:

$$
(\alpha h v)^{2}=A\left(h v-E_{g}\right)
$$

where $\alpha$ is the absorption coefficient, $h v$ is the photon energy, $A$ is a constant, and $E_{g}$ is the optical band gap. The optical band gap $E_{g}$ can be obtained by extrapolating the linear part of the curve to $(\alpha h v)^{2}=0$ if one plots $(h v)^{2} \sim h v$. The related curves for our samples are shown in Figure 5. The optical band gap energy for Ag- $\mathrm{ZnO}$ thin films is found to be in the range of $2.98 \mathrm{eV}$ to $3.12 \mathrm{eV}$. The band gap narrowed with

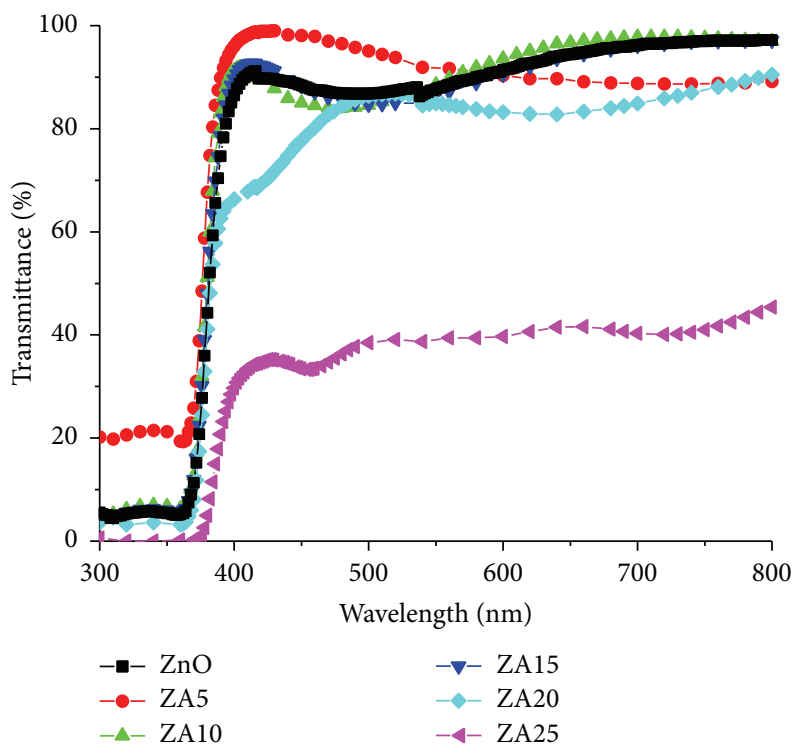

FIGURE 4: Transmittance spectra of Ag doped $\mathrm{ZnO}$ thin films.

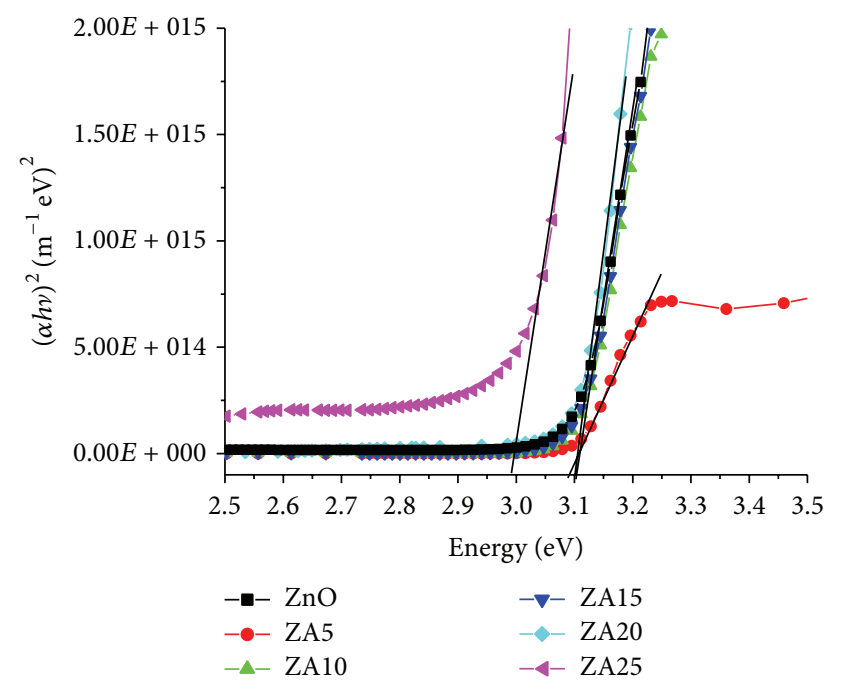

FIgure 5: Optical band gap of Ag- $\mathrm{ZnO}$ thin films.

increasing $\mathrm{Ag}$ contents. It means that $\mathrm{Ag}^{+}$was substituted into $\mathrm{Zn}^{2+}[13]$.

3.4. Photocatalytic Study. The photocatalytic process occurs when the $\mathrm{ZnO}$ material is irradiated by light that its energy is greater than the gap energy of $\mathrm{ZnO}$. Electrons $\left(\mathrm{e}^{-}\right)$and holes $\left(\mathrm{h}^{+}\right)$are formed in the conduction band and valence band, respectively. Then, holes will react with water to form $\mathrm{OH}^{*}$, while the electrons form superoxide $\left(\mathrm{O}_{2}{ }^{*-}\right)$ and subsequently form other reactive oxygen species $\left(\mathrm{H}_{2} \mathrm{O}_{2}\right.$ and $\left.\mathrm{OH}^{*}\right)$.

Holes and $\mathrm{OH}^{*}$ are highly reactive toward organic pollutants if they are in contact. The $\mathrm{C}-\mathrm{C}$ and $\mathrm{C}-\mathrm{H}$ bonds of $\mathrm{MB}$ adsorbed on the surface of $\mathrm{Ag}-\mathrm{ZnO}$ thin films can be destroyed by the oxidizing power of $\mathrm{OH}^{*}$ radicals leading to $\mathrm{CO}_{2}$ and $\mathrm{H}_{2} \mathrm{O}$ production [16]. Thin films were immersed in $40 \mathrm{~mL} \mathrm{MB}(10 \mathrm{ppm})$ and irradiated with $\mathrm{UV}$ (A) for $3 \mathrm{~h}$. 


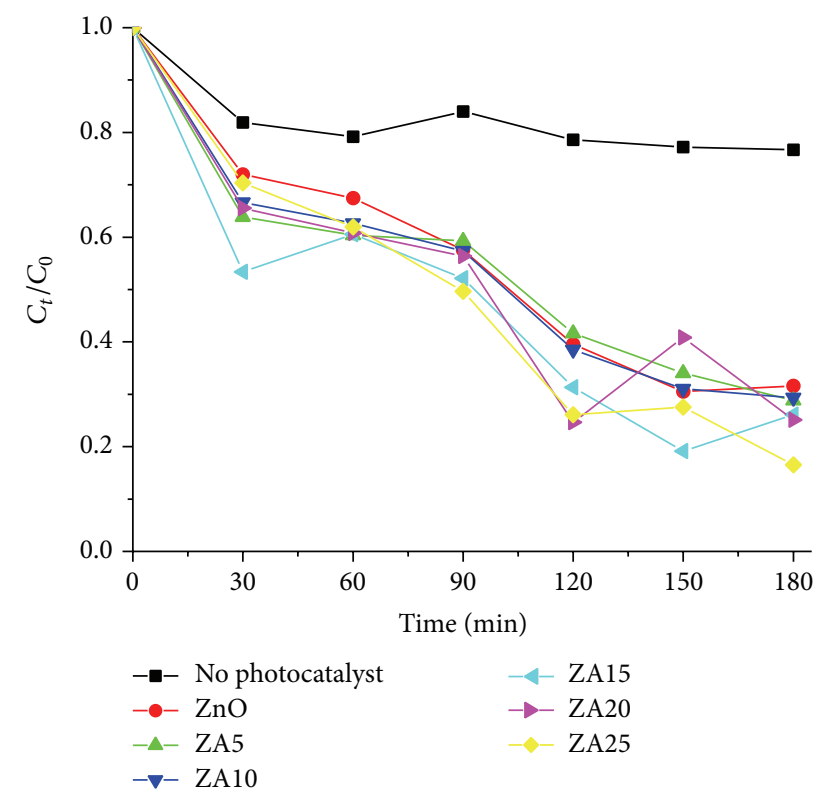

FIGURE 6: Degradation under UV irradiation with various films.

The photodegradation of the MB under UV (A) light irradiation was determined by measuring absorption spectra using UV/Vis spectrophotometer. Figure 6 shows the relationship between difference of concentration $\left(C_{t} / C_{0}\right)$ and irradiation time.

It can be seen that the photocatalytic degradation of $\mathrm{MB}$ by $\mathrm{Ag}-\mathrm{ZnO}$ thin films is up to $83 \%$ after $3 \mathrm{~h}$, while the MB without photocatalyst shows flat line about $18 \%$. This result informs that, without photocatalysts, $\mathrm{MB}$ does not significantly change. The addition of $\mathrm{Ag}$ on $\mathrm{ZnO}$ can improve the photocatalytic activity due to the active hydroxyl radical formation on the surface of $\mathrm{ZnO}$ [17]. On the other hand, there was also an influence of surface plasmon resonance (SPR) effect that can increase the photocatalytic activity by the increase of optical absorbance and charge carrier separation under UV irradiation [17].

Langmuir-Hinshelwood model describes the kinetic of photocatalytic degradation of $\mathrm{MB}$ and the photocatalytic degradation rate $(r)$ is given by the following equation [16]:

$$
r=-\frac{d C}{d t}=\frac{k_{r} K_{\mathrm{dye}} C}{1+K_{\mathrm{dye}} C}
$$

where $d C / d t$ is the degradation rate $\left(\mathrm{mgL}^{-1} \mathrm{~min}^{-1}\right), C$ is the dye concentration $\left(\mathrm{mgL}^{-1}\right)$ at the irradiation time $(t), k_{r}$ is the rate constant $\left(\mathrm{min}^{-1} \mathrm{gL}^{-1}\right)$, and $K_{\text {dye }}$ is the adsorption coefficient of the dye $\left(\mathrm{Lmg}^{-1}\right)$. Equation (7) is simplified into the first-order kinetic model with an apparent first-order rate constant $k_{\text {app }}\left(\mathrm{min}^{-1}\right)$ and at low concentrations $\left(K_{\text {dye }} C \ll 1\right)$ [16]:

$$
\ln \left(\frac{C_{t}}{C_{0}}\right)=-k_{r} K_{\text {dye }} t=-k_{\text {app }} t .
$$

The constants $k_{\text {app }}$ of $\mathrm{MB}$ are determined from the slopes of the linear plots $\ln \left(C_{t} / C_{0}\right)$ against the time $(t)$ (Table 3$)$.
TABLE 3: Apparent rate constants of methylene blue degradations.

\begin{tabular}{lcc}
\hline Thin films & $k_{\text {app }} \times 10^{-3}\left(\mathrm{~min}^{-1}\right)$ & $R^{2}$ \\
\hline ZnO & 6.79 & 0.95 \\
ZA5 & 6.38 & 0.94 \\
ZA10 & 6.78 & 0.95 \\
ZA15 & 8.02 & 0.81 \\
ZA20 & 7.14 & 0.76 \\
ZA25 & 9.69 & 0.95 \\
\hline
\end{tabular}

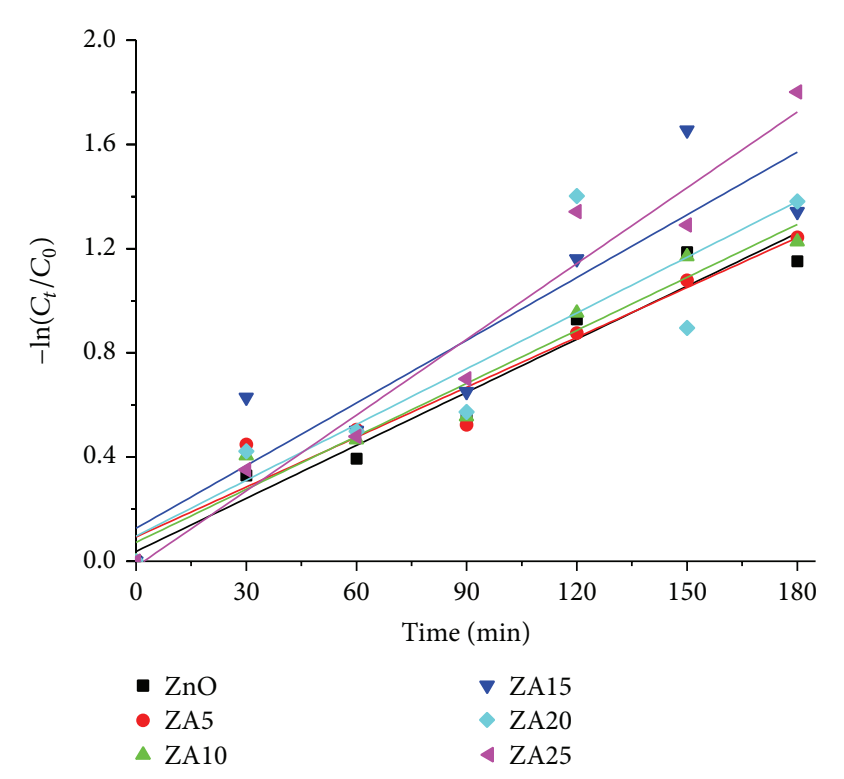

Figure 7: Kinetic degradation of MB under UV irradiation with various films.

Figure 7 shows that ZA25 has highest apparent first-order rate constant $\left(k_{\text {app }}\right)$ about $9.69 \times 10^{-3} \mathrm{~min}^{-1}$ and the correlation coefficient about 0.95 . These results are consistent with the results of the band gap ZA25, which is smaller than the other layers. The smaller gaps of energy band will facilitate the electrons movement from the valence to the conduction band, thus increasing the photocatalytic process.

\section{Conclusion}

Ag-ZnO thin films have been successfully synthesized onto glass substrates by using sol gel spray coating technique. From X-ray diffraction analysis, the films have polycrystalline spectra with wurtzite structure. The SEM images showed different morphology on each Ag doping concentration. The surface morphology for the sample $\mathrm{ZnO}$ and ZA20 shows thread-like morphology. Optical properties of $\mathrm{Ag}-\mathrm{ZnO}$ thin films show that transparency decreases along with increase of Ag content. The absorbance spectra of thin films are slightly shifted to higher wavelengths and ZA25 has lowest energy gap about $2.98 \mathrm{eV}$. The photocatalytic degradation of $\mathrm{MB}$ solution using $\mathrm{Ag}-\mathrm{ZnO}$ thin films was investigated under UV light irradiation. Sample ZA25 has the highest efficiency on photodegradation of MB. 


\section{Conflict of Interests}

The authors declare that there is no conflict of interests regarding the publication of this paper.

\section{Acknowledgment}

The authors would like to thank the Ministry of Research, Technology and Higher Education of Republic of Indonesia through Competence Grant 2015 no. 023.04.1.673453/2015 for funding of this work.

\section{References}

[1] G. Poongodi, R. M. Kumar, and R. Jayavel, "Structural, optical and visible light photocatalytic properties of nanocrystalline Nd doped ZnO thin films prepared by spin coating method," Ceramics International, vol. 41, no. 3, pp. 4169-4175, 2015.

[2] H. Sutanto, I. Nurhasanah, and E. Hidayanto, "Deposition of Ag 2 6 mol\%-doped $\mathrm{ZnO}$ photocatalyst thin films by thermal spray coating method for E. coli bacteria degradation," Materials Science Forum, vol. 827, pp. 3-6, 2015.

[3] S. Anandan, N. Ohashi, and M. Miyauchi, "ZnO-based visiblelight photocatalyst: band-gap engineering and multi-electron reduction by co-catalyst," Applied Catalysis B: Environmental, vol. 100, no. 3-4, pp. 502-509, 2010.

[4] M. G. Nair, M. Nirmala, K. Rekha, and A. Anukaliani, "Structural, optical, photo catalytic and antibacterial activity of $\mathrm{ZnO}$ and Co doped $\mathrm{ZnO}$ nanoparticles," Materials Letters, vol. 65, no. 12, pp. 1797-1800, 2011.

[5] H. Q. Bian, S. Y. Ma, Z. M. Zhang, J. M. Gao, and H. B. Zhu, "Microstructure and Raman scattering of Ag-doping $\mathrm{ZnO}$ films deposited on buffer layers," Journal of Crystal Growth, vol. 394, pp. 132-136, 2014.

[6] Y. Zhang, Z. Zhang, B. Lin, Z. Fu, and J. Xu, "Effects of Ag doping on the photoluminescence of $\mathrm{ZnO}$ films grown on $\mathrm{Si}$ substrates," The Journal of Physical Chemistry B, vol. 109, no. 41, pp. 19200-19203, 2005.

[7] J. Fan and R. Freer, "The roles played by Ag and Al dopants in controlling the electricalproperties of $\mathrm{ZnO}$ varistors," Journal of Applied Physics, vol. 77, no. 9, pp. 4795-4800, 1995.

[8] Q. Li, Y. Wang, J. Liu, W. Kong, and B. Ye, "Structural and magnetic properties in $\mathrm{Mn}$-doped $\mathrm{ZnO}$ films prepared by pulsed-laser deposition," Applied Surface Science, vol. 289, pp. 42-46, 2014.

[9] S. Vijayalakshmi, S. Venkataraj, M. Subramanian, and R. Jayavel, "Physical properties of Zinc Doped thin oxide films prepared by spray pyrolysis technique," Journal of Physics D: Applied Physics, vol. 41, no. 1, pp. 1-7, 2008.

[10] J.-P. Biethan, V. P. Sirkeli, L. Considine, D. D. Nedeoglo, D. Pavlidis, and H. L. Hartnagal, "Photoluminescence study of $\mathrm{ZnO}$ nanostructures grown on silicon by MOCVD," Materials Science and Engineering: B, vol. 177, no. 8, pp. 594-599, 2012.

[11] H. Sutanto, I. Nurhasanah, and H. Hadiyanto, "Effect of Mn concentration on magnetic and structural properties of GaN:Mn deposited on silicon substrate using chemical solution deposition method," Romanian Journal of Materials, vol. 44, no. 3, pp. 298-303, 2014.
[12] M. Karyaoui, A. Mhamdi, H. Kaouach et al., "Some physical investigations on silver-doped $\mathrm{ZnO}$ sprayed thin films," Materials Science in Semiconductor Processing, vol. 30, pp. 255-262, 2015.

[13] H. Q. Bian, S. Y. Ma, F. M. Li, and H. B. Zhu, "Influence of ZnO buffer layer on microstructure and raman scattering of $\mathrm{ZnO}: \mathrm{Ag}$ film on Si substrate," Superlattices and Microstructures, vol. 58, pp. 171-177, 2013.

[14] N. L. Tarwal and P. S. Patil, "Enhanced photoelectrochemical performance of Ag-ZnO thin films synthesized by spray pyrolysis technique," Electrochimica Acta, vol. 56, no. 18, pp. 6510-6516, 2011.

[15] R. Shidpour, A. Simchi, F. Ghanbari, and M. Vossoughi, "Photodegradation of organic dye by zinc oxide nanosystems with special defect structure: effect of the morphology and annealing temperature," Applied Catalysis A: General, vol. 472, pp. 198204, 2014.

[16] S. Boumaza, F. Kaouah, D. Hamane, M. Trari, S. Omeiri, and Z. Bendjama, "Visible light assisted decolorization of azo dyes: direct Red 16 and Direct blue 71 in aqueous solution on the $p$ - $\mathrm{CuFeO}_{2} / n-\mathrm{ZnO}$ system," Journal of Molecular Catalysis A: Chemical, vol. 393, pp. 156-165, 2014.

[17] J. Lu, H. Wang, S. Dong, F. Wang, and Y. Dong, "Effect of $\mathrm{Ag}$ shapes and surface compositions on the photocatalytic performance of $\mathrm{Ag} / \mathrm{ZnO}$ nanorods," Journal of Alloys and Compounds, vol. 617, pp. 869-876, 2014. 


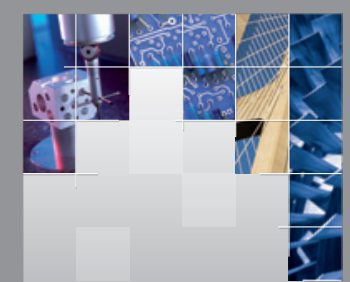

\section{Enfincering}
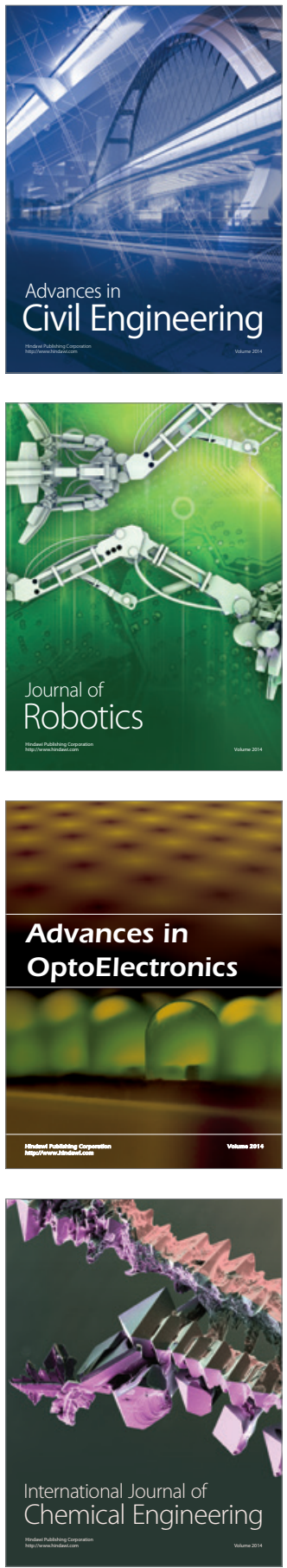

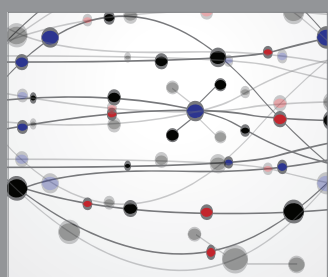

The Scientific World Journal

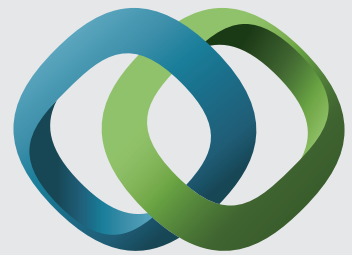

\section{Hindawi}

Submit your manuscripts at

http://www.hindawi.com
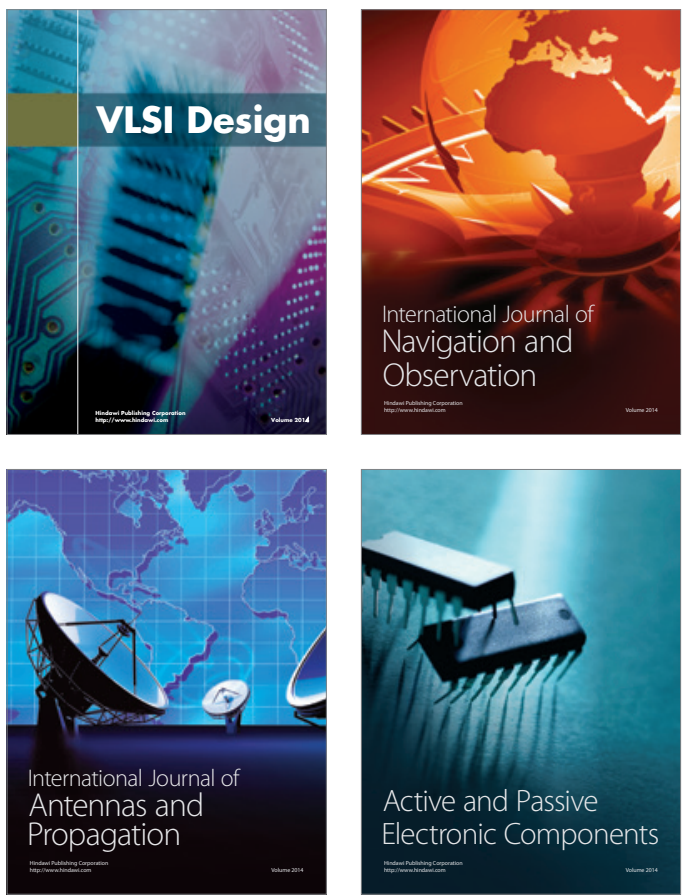
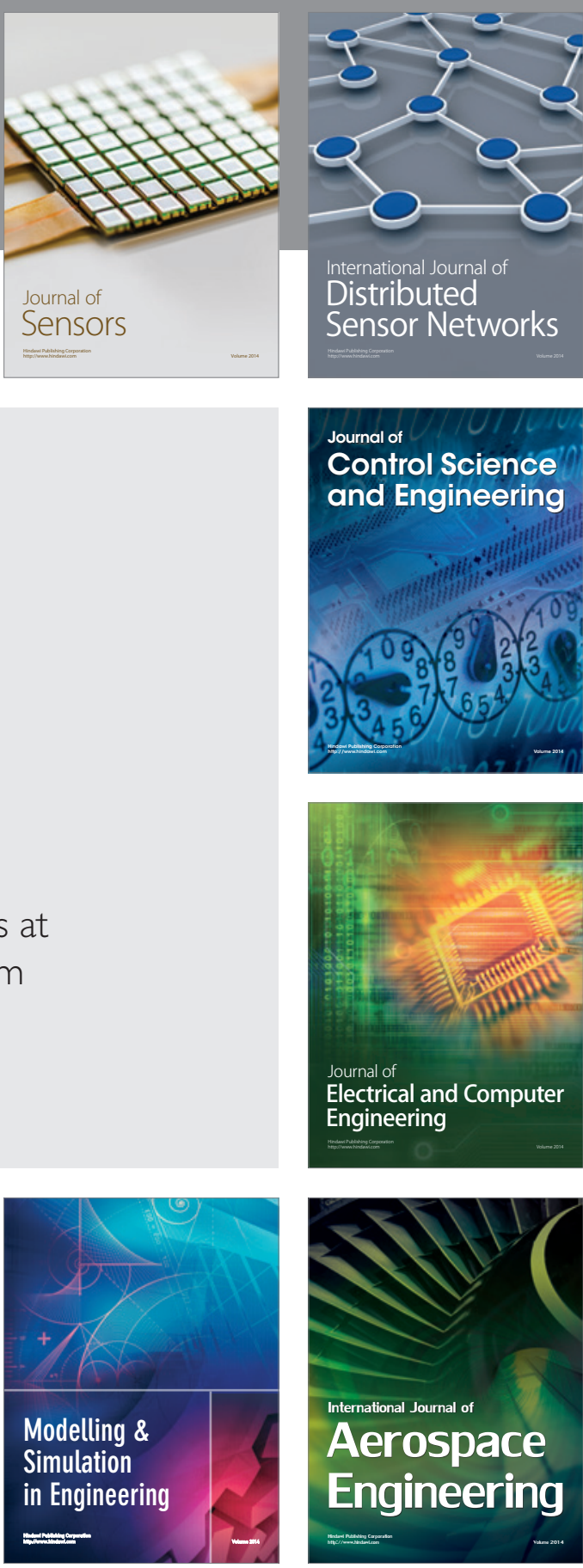

International Journal of

Distributed

Sensor Networks

Journal of

Control Science

and Engineering
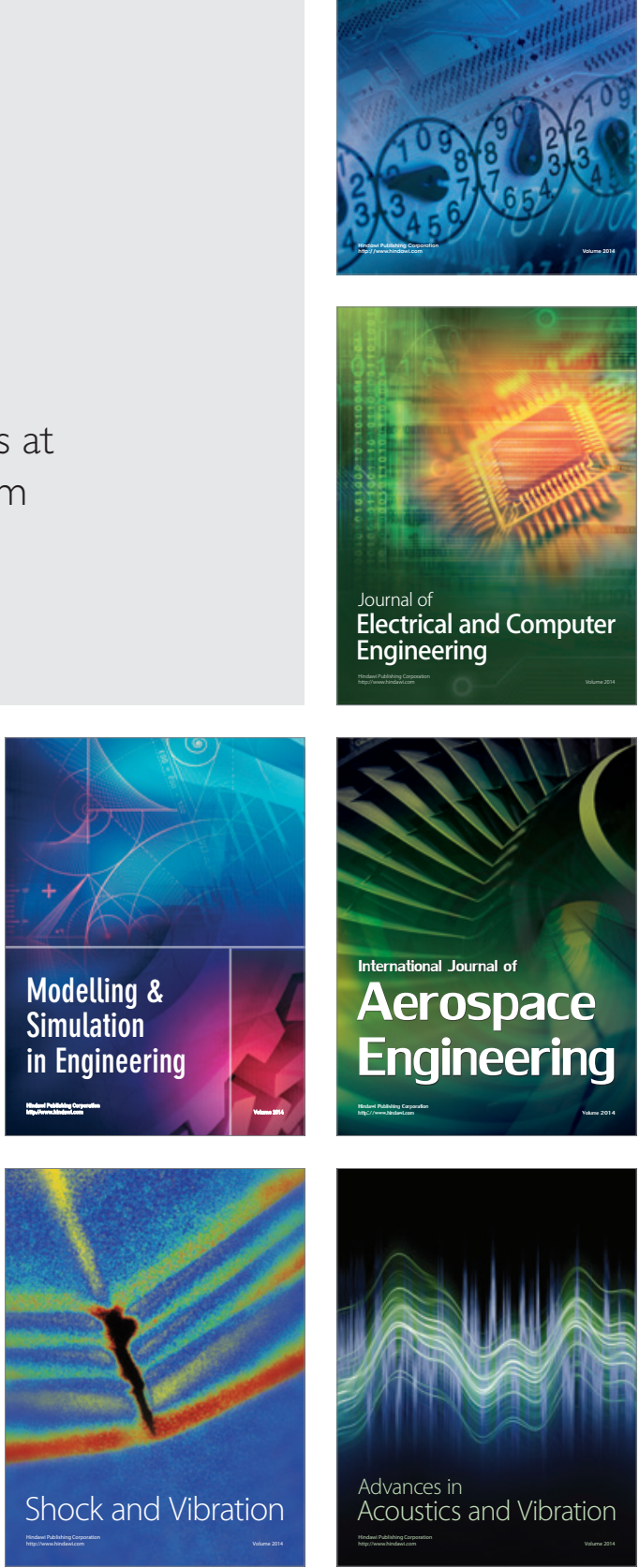